\title{
Importance of considering nutrient loadings from small watersheds to a lake - A case study of the Lake Shinji watershed, Shimane Prefecture, Japan
}

\author{
Hiroaki Somura ${ }^{1 *}$, Hidenobu Kunii², Yasumichi Yone ${ }^{3}$, Ikuo Takeda ${ }^{3}$, Hirokazu Sato ${ }^{3}$ \\ (1. Graduate School of Environmental and Life Science, Okayama University, Okayama 7008530, Japan; 2. Estuary Research Center, \\ Shimane University, Matsue 6908504, Japan; 3. Faculty of Life and Environmental Science, Shimane University, Matsue 6908504, Japan)
}

\begin{abstract}
Nutrient loadings from upstream watersheds can have significant impacts on the water quality of receiving water bodies. Usually, a major river is selected as the target for water quality studies, and the impact of minor rivers tends to be ignored. It is very important to evaluate whether the impact of small rivers on the downstream water quality is negligible. River water sampling and discharge modeling using SWAT were used to analyze the contribution of small rivers to water quality in a receiving lake. From this analysis, it was determined that the inflowing total nitrogen (TN) and total phosphorus (TP) concentrations from all target rivers exceeded the lake water environmental standards set by the Ministry of the Environment. The contribution of suspended sediment (SS) and TN loads from small rivers did not vary markedly compared with their relative discharge contributions to the lake, at approximately $20 \%$. However, the impact on TP loads to the lake from small rivers was $9.1 \%$ higher than their relative flow contributions, accounting for $28.2 \%$ of the TP loading. Thus, there is a potential to underestimate the impact of ungauged small rivers if only the major river is selected to evaluate the downstream lake water quality.
\end{abstract}

Keywords: suspended sediment (SS), total nitrogen (TN), total phosphorus (TP), watershed management, SWAT model DOI: $10.25165 /$ j.ijabe.20181105.4351

Citation: Somura H, Kunii H, Yone Y, Takeda I, Sato H. Importance of considering nutrient loadings from small watersheds to a lake - A case study of the Lake Shinji watershed, Shimane Prefecture, Japan. Int J Agric \& Biol Eng, 2018; 11(5): 124-130.

\section{Introduction}

Downstream lake environments are often characterized by low water quality in many areas of the world. One of the reasons for environmental degradation in lakes is the nutrient load (e.g., from nitrogen and phosphorus) inflowing from upstream watersheds. Nutrient loads in rivers occur due to natural and anthropogenic discharges from nonpoint sources (agricultural and livestock) and point sources (industrial and domestic sewage) ${ }^{[1-5]}$. Rivers then convey the nutrient load downstream via river channels, resulting in potential eutrophication of lakes or coastal systems if the loads are excessive. Eutrophication has many negative effects on aquatic ecosystems, the most obvious of which is the increased growth of algae and aquatic weeds, which interfere with the use of water for fishing, recreation, industry, agriculture, and human

Received date: 2018-04-24 Accepted date: 2018-08-22

Biographies: Hidenobu Kunii, PhD, Affiliate Professor, research interest: conservation ecology of aquatic macrophytes, Email: kunii@ soc.shimane-u.ac.jp; Yasumichi Yone, PhD, Associate Professor, research interest: forest management, remote sensing, UAV, photogrammetry, deep learning, Email: yone@life.shimane-u.ac.jp; Ikuo Takeda, PhD, Professor, research interest: rural engineering, Email: ikuotake@life.shimane-u.ac.jp; Hirokazu Sato, PhD, Assistant Professor, research interest: flood control planning on premise of inundation, Email: satohiro@life.shimane-u.ac.jp.

*Corresponding author: Hiroaki Somura, $\mathrm{PhD}$, Associate Professor, research interest: irrigation and drainage, efficient water allocation in agricultural fields (especially in semi-arid region), watershed (water resources) management, water quality issues in a river basin and/or an agricultural area, land use management and water quality, climate change, Graduate School of Environmental and Life Science, Okayama University, 3-1-1 Tsushimanaka, Kita-ku, Okayama-shi, Okayama 7008530, Japan. Tel: +81-86-251-8876, Email: somura@ okayama-u.ac.jp. consumption ${ }^{[6]}$. In addition, eutrophication is a factor that causes the loss of aquatic biodiversity ${ }^{[7]}$. The impairment of aquatic resources by eutrophication can thus have substantial economic effects $^{[8]}$. In marine ecosystems, algal blooms (red or brown tides) can cause widespread problems by releasing toxins and the onset of anoxia when oxygen is consumed as dead algae decompose ${ }^{[9]}$. In freshwater, blooms of cyanobacteria (blue-green algae) are a prominent symptom of eutrophication ${ }^{[10-, 11]}$.

To develop a conservation strategy to improve lake water quality, it is necessary to understand the factors affecting the water quality of rivers flowing into a lake. In other words, all tributaries and/or sources to a lake or impoundment should be considered in an overall assessment of water quality. However, in most cases, only the impact of the water quality of major contributing rivers is considered in such assessments; minor rivers are ignored because of the cost of measurement and their potential small influence on a lake water environment. Therefore, due to a lack of data on their quality and quantity, the influence of small rivers on lake water environments has hardly been quantified. In some cases, interventions may be needed for smaller watersheds that seem inconsequential at first glance but could be contributing pollutants preventing establishment desirable water quality levels until small sources are remediated.

In this study, nutrient loadings from the largest contributing river and many small rivers in a lake watershed are compared to understand the influence of small watersheds on downstream lake water quality. The Soil and Water Assessment Tool (SWAT) ecohydrological model ${ }^{[12-14]}$ was applied to the Lake Shinji watershed to estimate the discharges from inflowing rivers. The ability of the model to reproduce river discharge in ungauged or poorly gauged watersheds, using parameter sets obtaining from 
gauged watersheds within the same region, has been confirmed by previous studies ${ }^{[15,16]}$. The specific objectives of this study are: (1) measure the concentrations of suspended sediment (SS), total nitrogen (TN) and total phosphorus (TP) entering Lake Shinji from different source streams, based on a water sampling field investigation and laboratory analysis; and 2) estimate the contribution of nutrient loads from the multiple source streams to Lake Shinji during 2013 and 2014, as a function of the measured concentrations and simulated discharge using SWAT.

\section{Study area}

Lake Shinji is located in the eastern region of the Shimane Prefecture, Japan, and is a representative brackish lake (the third largest in surface area in Japan), with an area of $79.1 \mathrm{~km}^{2}$ (Figure 1). Water quality observation began in the 1970 s, and most parameters are measured monthly at five points in the lake. At the central observatory, annual average concentrations of TN and TP are about $0.53 \pm 0.067 \mathrm{mg} / \mathrm{L}$ and $0.044 \pm 0.0084 \mathrm{mg} / \mathrm{L}$, and the water quality of the lake has never met the environmental standards for TN and TP, which are $0.4 \mathrm{mg} / \mathrm{L}$ and $0.03 \mathrm{mg} / \mathrm{L}$, respectively ${ }^{[17]}$. In addition, blooms of both of blue-green algae and red tide have occasionally been observed ${ }^{[18]}$.

The watershed has an area of approximately $1194 \mathrm{~km}^{2}$, of which $81 \%$ is forest, $13 \%$ is paddy fields, $2 \%$ is upland crops, and $2 \%$ is residential. Ninety-six percent of the forest is privately owned, of which $48 \%$ is artificial plantation, almost entirely coniferous. The distribution of land use within the drainage areas to the outlets is listed in Table 1 and shown in Figure2 (left side). The land use types are generally very similar between the sub-watersheds and are also consistent with typical land use proportions in rural areas of Japan. The major land use is forest, which ranges from $69.0 \%$ to $87.6 \%$ of the overall land use of each sub-watershed. The second largest land use is agricultural fields, which range from $10.1 \%$ to $25.6 \%$ of a given sub-watershed area and consist primarily of rice paddy fields.

More than 20 rivers flow into the lake. The largest contributor to the ecosystem and lake environment is the Hii River which drains an area of approximately $911 \mathrm{~km}^{2}$. The length of the river from the source, Mt. Sentsu at $1143 \mathrm{~m}$ asl, to the Otsu river discharge observation station is approximately $63 \mathrm{~km}$. Observations of water level and discharge at the Otsu station began in September 1893, and water quality has been observed since November 1967, so long-term data sets have been accumulated. On the other hand, only three water level observatories are set around Lake Shinji for flood warning, and no quality data is observed.

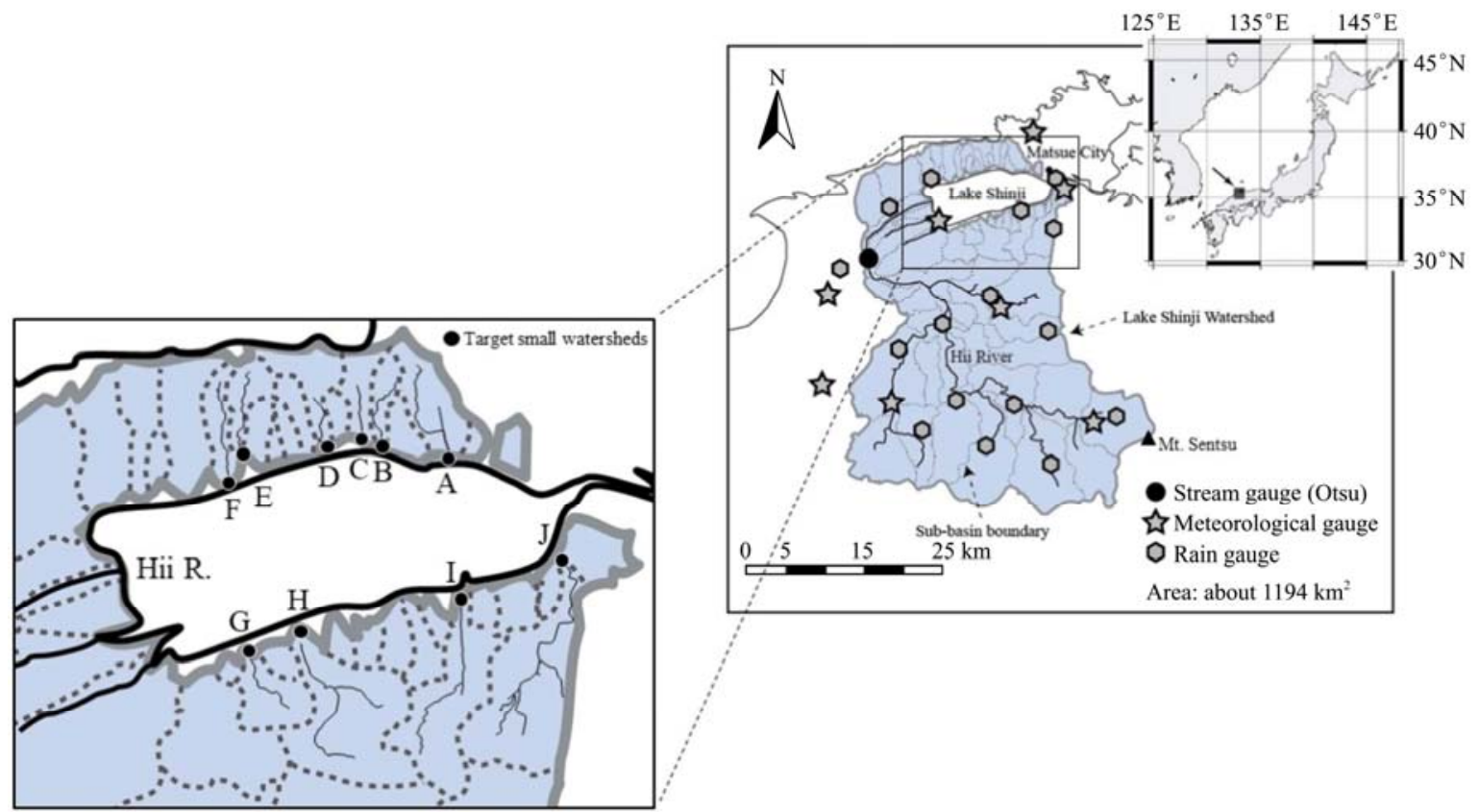

Figure 1 Location of the study area

Table 1 Watershed size $\left(\mathrm{km}^{2}\right)$, land use ratio (\%), and existence of small-scale community sewage system in the target sub-watersheds

\begin{tabular}{|c|c|c|c|c|c|c|c|c|c|}
\hline & Site & Area & Forest & Paddy Fields & Upland Fields & Residential Area & Others & Water & Upstream sewage system \\
\hline \multirow{5}{*}{ North side } & A & 7.31 & 69.0 & 24.0 & 1.6 & 2.1 & 0.8 & 2.5 & Yes \\
\hline & $\mathrm{B}$ & 2.25 & 76.5 & 18.8 & 0.9 & 2.8 & 0.9 & 0.1 & No \\
\hline & $\mathrm{C}$ & 3.50 & 83.3 & 13.1 & 0.6 & 2.0 & 0.6 & 0.4 & No \\
\hline & $\mathrm{D}$ & 5.69 & 84.0 & 11.2 & 2.9 & 1.8 & 0.0 & 0.1 & Yes \\
\hline & $\mathrm{E}$ & 3.91 & 71.7 & 17.2 & 8.2 & 2.0 & 0.9 & 0.0 & No \\
\hline \multicolumn{2}{|c|}{ Hii R. Otsu } & 911 & 87.6 & 8.6 & 1.5 & 1.0 & 0.3 & 1.0 & Yes \\
\hline \multirow{4}{*}{ South side } & G & 5.96 & 80.2 & 15.1 & 0.9 & 0.8 & 3.0 & 0.0 & Yes \\
\hline & $\mathrm{H}$ & 16.92 & 84.8 & 10.9 & 1.5 & 0.9 & 1.2 & 0.7 & Yes \\
\hline & I & 13.40 & 83.7 & 9.5 & 1.1 & 4.8 & 0.9 & 0.0 & No \\
\hline & $\mathrm{J}$ & 18.87 & 72.8 & 19.8 & 2.3 & 2.4 & 1.3 & 1.4 & Yes \\
\hline
\end{tabular}



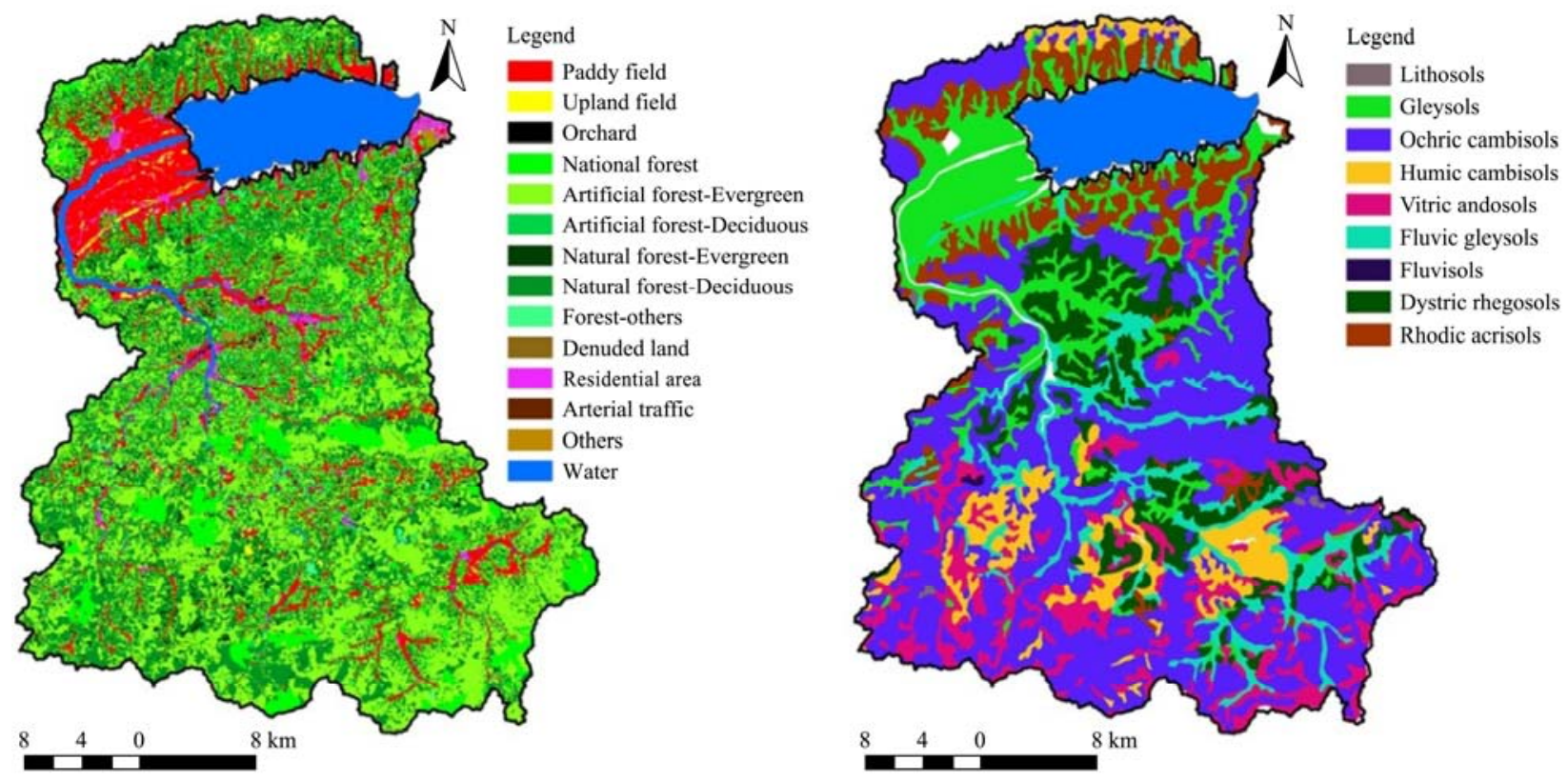

Figure 2 Modified GIS land use data (left) and soil data (right)

During June and July, a stationary seasonal rain front forms over the district. This remains stationary for long periods and often causes intense rainstorms. Typhoons may approach the region especially in August and September, and strong winds and heavy rain can cause extensive damage. In winter, snow clouds form over the region and produce heavy snowfalls. In addition, winter precipitation tends to be higher than in other regions. The average annual precipitation varies from approximately $1700 \mathrm{~mm}$ to $2000 \mathrm{~mm}$, and average annual maximum and minimum temperatures are $18^{\circ} \mathrm{C}$ and $9^{\circ} \mathrm{C}$, respectively.

\section{Methodology}

\subsection{River water sampling and water quality analysis}

River water sampling was conducted once a month from May 2013 to December 2014 at 11 sites (10 small rivers and the Hii River). Water samples were collected from downstream stretches of the rivers using a bucket or direct sampling. The locations were carefully chosen to avoid the influence of backwater from Lake Shinji. Samples were immediately transported to our laboratory where they were filtered using glass fiber filters (Advantec GS-25) to separate the particles and dissolved substances. The separated particles were dried and weighed to determine the concentration of SS. TN concentrations were determined through the ultraviolet spectrophotometry method using potassium peroxydisulfate (JIS K 0102). Potassium peroxydisulfate was also used in the molybdenum blue method to determine TP concentrations.

\subsection{Simulation of ungauged small river discharges}

There are several ways to approximate river discharges from a field survey, including measuring flow velocity at a cross-section of a water body or creating a water depth-discharge curve. However, discharges obtained from these methods only provide information during the survey periods and cannot easily be extrapolated for non-survey periods. Discharge modeling is one way to estimate river discharges and overcome this weakness. Modeling can be an efficient and effective estimation tool if many rivers are flowing into a lake and measurement of all rivers during field surveys is difficult.

The Lake Shinji watershed was divided into 64 sub-watersheds in the SWAT model setup. The values of model parameters were adjusted using monthly discharges from the Otsu observatory (an outlet of the Hii River) from 1988 to 2011. Parameter values were not modified individually for the other small rivers due to a lack of observed data. The warm-up period was set from 1985 to 1987, and the calibration and validation periods were set from 1988 to 1997 and from 1998 to 2011, respectively. At first, parameter values were calibrated manually until simulated river discharges became close to observed values, and then SUFI2 in SWAT-CUP ${ }^{[19]}$, a SWAT-compatible sensitivity analysis and calibration software, was used to further calibrate the parameter values.

After calibration and validation, the small river discharges were simulated for the target period, 2013-2014. A dam began operating in the upstream region of the Hii River in April 2012, after which time the downstream hydrograph was artificially controlled by the dam. This means that small river discharges simulated using Hii River parameter values post 2012 would not represent the natural rainfall-discharge relationship. Therefore, parameter values were calibrated and validated from 1988 to 2011 under pre-dam conditions.

\subsection{Estimated contribution of nutrient loads from watersheds}

The contribution of nutrient loads from the river watersheds to the downstream lake was estimated using the average observed water quality from the Otsu observation station and 10 small rivers, and the annual discharges of the small rivers and the Hii River from SWAT. Then estimated nutrient loading from the small rivers and the Hii River were compared.

\subsection{Input data description}

SWAT requires spatial data sets, including a digital elevation model (DEM) and land cover and soil maps. The DEM was prepared using a digital elevation map (10 $\mathrm{m}$ grid) created from a 1:25 000 topographic map published by the Geospatial Information Authority of Japan (GSI) ${ }^{[20]}$. Land use data were based on digital national land use maps identifying paddy fields, non-paddy fields (upland fields and orchards), denuded land, forests, and water, and prefectural information on the varieties of tree species summarized in 2010. The land use maps were based on the 1:25000 topographic map and 1:100 subdivision plat data from 2006, obtained from the National Land Information Office of the 
Ministry of Land, Infrastructure, Transport and Tourism (MLIT) ${ }^{[21]}$ and from Shimane Prefecture (Figure 2, left). Although the percentage of agricultural land might change year by year, the value was kept constant during the simulation period, because the target watershed is located in a rural and mountainous area with minimal development.

Soil data were obtained from the 1:200 000 Fundamental Land Classification Survey soil map prepared by the MLIT ${ }^{[22]}$. The 24 soil types were categorized into nine groups: dystric rhegosols, fluvic gleysols, gleysols, fluvisols, humic cambisols, lithosols, ochric cambisols, rhodic acrisols, and vitric andosols (Figure 2, right).

Meteorological data were obtained from two sources: the Japan Meteorological Agency (JMA) ${ }^{[23]}$ and the MLIT. Data obtained from the JMA, such as precipitation, temperature, wind speed, and actual sunshine duration, were monitored by the Automated Meteorological Data Acquisition System (AMeDAS). Data from 21 precipitation gauges and three air temperature and wind speed gauges located in or near the watersheds were used. Relative humidity was recorded at Matsue City, which is located approximately $30 \mathrm{~km}$ NE of the Hii River watershed. Since no stations within the Hii River watershed collected solar radiation data, this was calculated using the Angstrom formula ${ }^{[24]}$ using data collected by Shimane University and the actual sunshine duration in the watershed. Climate data gaps were filled using the weather generator included in SWAT. For the weather generator, input data were statistically generated from 20 years' data collected in or near the watersheds.

River discharge data collected at the Otsu gauging station were obtained from the MLIT Izumo River Office.

\subsection{Model performance evaluation}

SWAT was calibrated and validated using observed monthly discharge data. Initial assessment of the results was performed using graphical techniques, which provide a visual comparison of simulated and observed discharge data and a preliminary overview of the model performance ${ }^{[25]}$. The coefficient of determination $\left(R^{2}\right)$, Nash-Sutcliffe efficiency (NSE), and percent bias (PBIAS) were then used to statistically evaluate the model performance.

The $R^{2}$ value is an indicator of the strength of the relationship between the observed and simulated values. Values of $R^{2}$ range from zero to one, with a value of zero indicating no correlation and a value of one indicating that the predicted dispersion equals the measured dispersion ${ }^{[26]}$. Gassman et al. ${ }^{[27-28]}$ and Bressiani et al. ${ }^{[29]}$ reported that daily $R^{2}$ statistics had been used to evaluate SWAT in many studies.

The NSE value ${ }^{[30]}$ indicates how well the plot of the observed values versus the simulated values fits the unit slope line. The NSE values range from $-\infty$ to 1 , with values less than or close to zero indicating unacceptable or poor model performance, and a value of one representing a perfect match. The NSE value is calculated using Equation (1):

$$
N S E=1.0-\left(\sum_{i=1}^{n}\left(Y_{o b s, i}-Y_{c a l, i}\right)^{2} / \sum_{i=1}^{n}\left(Y_{o b s, i}-Y_{\text {obs_mean }}\right)^{2}\right)
$$

where, $n$ is the number of observations; $Y_{o b s, i}$ is the observation at time $i ; Y_{\text {cal }, i}$ is the simulated value at time $i$, and $Y_{\text {obs_mean }}$ is the mean value of the observed data.

The PBIAS is used to determine if the average tendency of the simulated data is larger or smaller than their observed counterparts $^{[31]}$. The optimal value of PBIAS is zero, with low values indicating an accurate model simulation. Positive values indicate model underestimation bias, whereas negative values indicate model overestimation bias ${ }^{[31]}$. The PBIAS is calculated using Equation (2):

$$
\text { PBIAS }=\left(\sum_{i=1}^{n}\left(Y_{o b s, i}-Y_{c a l, i}\right) \times 100 / \sum_{i=1}^{n}\left(Y_{o b s, i}\right)\right)
$$

where, $n$ is the number of observed values, and the other parameters are as per Equation (1).

Moriasi et al. ${ }^{[32]}$ developed model evaluation guidelines using systematic quantification of accuracy in watershed simulations. They suggested that the performance of a model simulation could be judged as "satisfactory" if $R^{2}>0.60$, NSE $>0.50$, and PBIAS is $\pm 15 \%$ for streamflow at a monthly time step.

\section{Results and discussion}

\subsection{Water quality in the Hii River and small rivers}

Analyte concentrations in all target rivers from May 2013 to December 2014 exceeded the environmental standards set by the Ministry of the Environment (Table 2). For TN, for which the standard is defined as $0.4 \mathrm{mg} / \mathrm{L}$ in Lake Shinji, the average concentrations varied from $0.49 \mathrm{mg} / \mathrm{L}$ to $1.86 \mathrm{mg} / \mathrm{L}$ among the target rivers. Watersheds $\mathrm{A}, \mathrm{D}$, and $\mathrm{F}$ showed the highest concentrations among the watersheds. For TP, for which the standard is defined as $0.03 \mathrm{mg} / \mathrm{L}$, the concentrations ranged between $0.034 \mathrm{mg} / \mathrm{L}$ and $0.24 \mathrm{mg} / \mathrm{L}$. Like TN, watersheds A and $\mathrm{D}$ showed the highest TP concentrations among the watersheds. The results indicate that the water flowing into Lake Shinji has relatively high nutrient concentrations. For SS, there is no defined standard and the concentrations varied from $5.8 \mathrm{mg} / \mathrm{L}$ to $16.5 \mathrm{mg} / \mathrm{L}$. Most of the sampling days coincided with steady river discharge conditions, although concentrations can change with unsteady conditions, e.g., in response to rain.

Table 2 Average water quality $(\mathrm{mg} / \mathrm{L})$ of the Hii river and the 10 small target rivers.

\begin{tabular}{|c|c|c|c|c|c|c|c|c|c|c|c|}
\hline & \multicolumn{6}{|c|}{ North side } & \multirow{2}{*}{$\begin{array}{c}\text { Hii R. } \\
\text { Otsu } \\
(20)\end{array}$} & \multicolumn{4}{|c|}{ South side } \\
\hline & A (19) & B (20) & C (20) & $\mathrm{D}(19)$ & E (19) & F (20) & & $\mathrm{G}(20)$ & H (20) & I (20) & $\mathrm{J}(20)$ \\
\hline $\mathrm{TN}$ & 1.86 & 0.87 & 0.73 & 1.02 & 0.73 & 1.05 & 0.57 & 0.51 & 0.49 & 0.52 & 0.60 \\
\hline Average & \multicolumn{6}{|c|}{1.05} & 0.51 & \multicolumn{4}{|c|}{0.56} \\
\hline $\mathrm{TP}$ & 0.24 & 0.07 & 0.07 & 0.14 & 0.07 & 0.08 & 0034 & 0.08 & 0.06 & 0.05 & 0.04 \\
\hline Average & \multicolumn{6}{|c|}{0.11} & 0.034 & \multicolumn{4}{|c|}{0.056} \\
\hline SS & 16.5 & 15.4 & 8.3 & 10.0 & 5.8 & 11.1 & 00 & 6.3 & 7.4 & 6.7 & 9.0 \\
\hline Average & \multicolumn{6}{|c|}{11.2} & 9.9 & \multicolumn{4}{|c|}{7.4} \\
\hline
\end{tabular}
Numbers in parenthesis show the number of samples from each river

Statistically significant differences in TN and TP were detected between many sites; however, differences in SS concentration were not significant (Figure 3). Watershed A showed higher variation in both TN and TP concentration during the research period, and watershed D also showed a relatively high variation in TP. Nutrient input from forest is considered to have a low impact on 
water quality, and the magnitude of the impact is similar among all sub-watersheds. Possible main sources of nutrients are inputs to the agricultural sector such as fertilizers (a non-point source) and discharge from small-scale community sewage systems after treatment (point sources). A small-scale community sewage system is located very close to the water sampling site in watershed A, thus water quality could be influenced by sewage discharge explaining the larger variation in nitrogen and phosphorus concentrations observed during the research period.
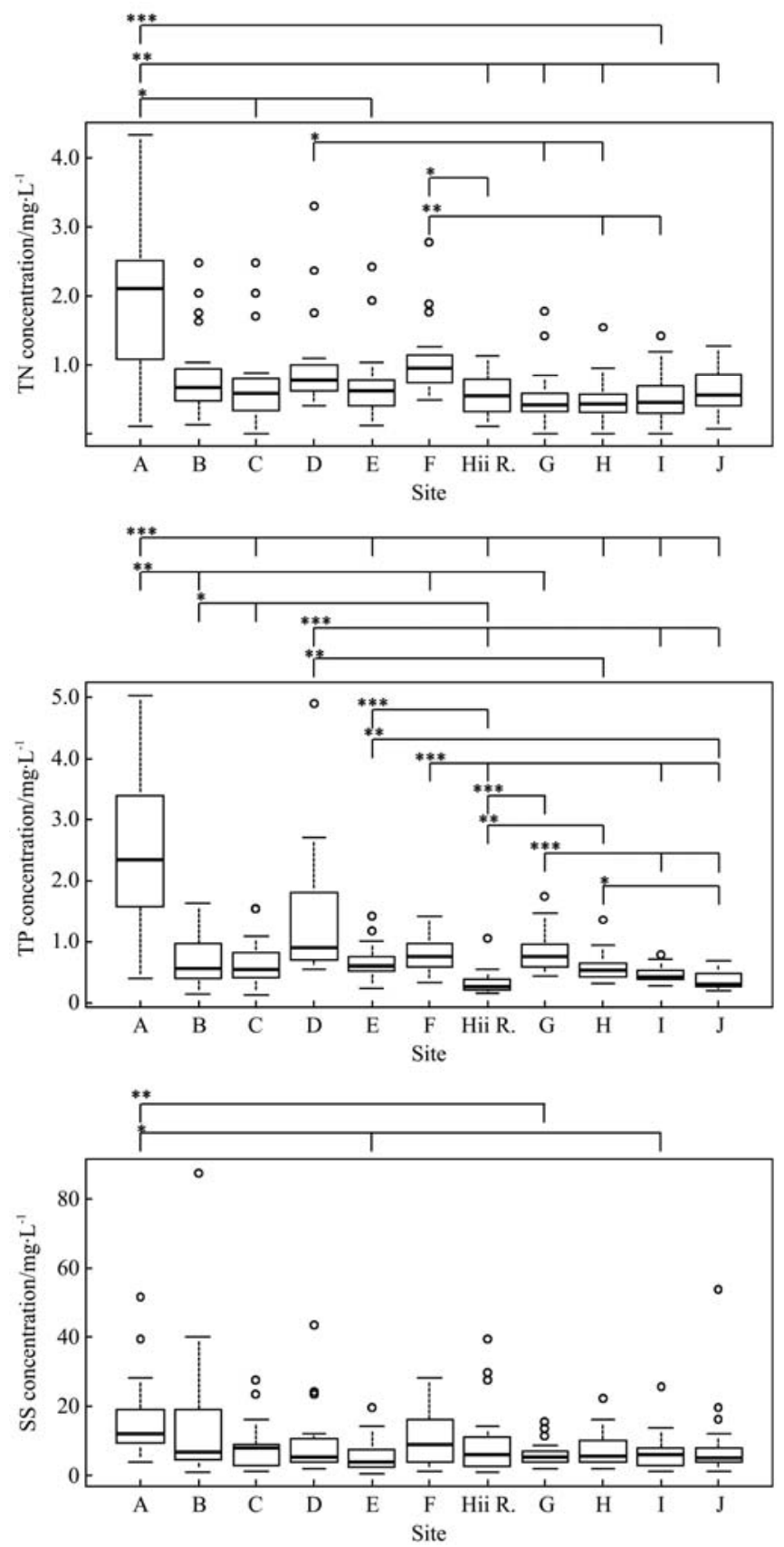

Note: Box $=25$ th and 75 th percentiles; bar $=$ minimum and maximum values; $\operatorname{dot}=$ outlier. Kruskal-Wallis test with the Bonferroni adjustment, $* p<0.05$, $* * p<0.01, * * * p<0.001$.

Figure $3 \mathrm{TN}, \mathrm{TP}$ and $\mathrm{SS}$ concentrations in each river

Relationships between land use types and water qualities were confirmed, although no statistically significant strong correlations were detected. The area of paddy fields was weakly positively correlated with all water quality parameters $(p<0.01)$, and the area of forest was weakly negatively correlated with water quality parameters (TN and TP: $p<0.01$; SS: $p<0.05$ ). In addition, a very weak negative correlation with statistical significance $(p<0.01)$ was detected between nutrient concentrations and sub-watershed size. The relationship between the location of sewage systems in the sub-watersheds and water quality was investigated, and a statistically significant difference was not detected for averages of SS and TN but was detected for TP $(p<0.001)$. Thus nutrient input from sewage systems to receiving rivers was considered to have a negative impact on TP concentrations.

\subsection{Simulation of river discharges}

Monthly simulated and observed discharges are shown in Figure 4, and the evaluation statistics are shown in Table 3. Figure 4 shows that the river discharge fluctuations were adequately captured in both the calibration and validation periods. All statistical results except for PBIAS during the validation period satisfied Moriasi's criteria for satisfactory model performance ${ }^{[32]}$. The PBIAS indicates that the model tended to slightly underestimate river discharge at the Otsu observatory during the validation period.

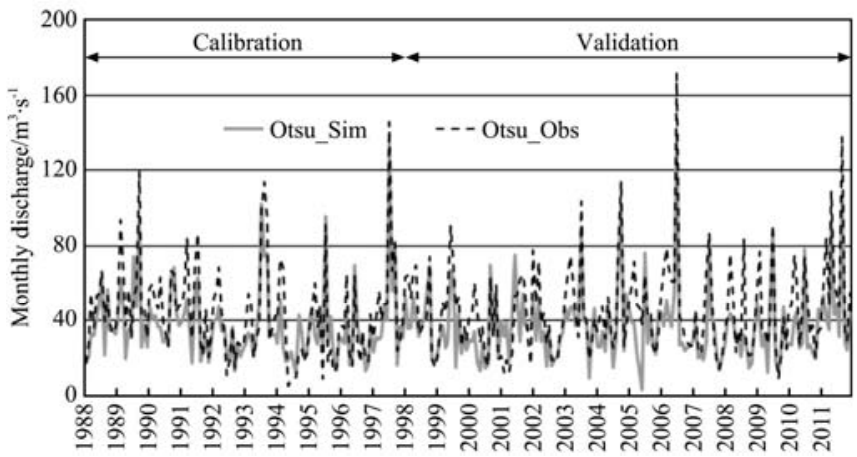

Figure 4 Hii River simulated and observed discharges with a monthly time step

Table 3 Statistical evaluation of the model performance

\begin{tabular}{cccc}
\hline & $\begin{array}{c}\text { Satisfactory } \\
\text { criteria }^{\mathrm{a}}\end{array}$ & $\begin{array}{c}\text { Calibration } \\
1988-1997\end{array}$ & $\begin{array}{c}\text { Validation } \\
1998-2011\end{array}$ \\
\hline NSE & $>0.50$ & 0.70 & 0.57 \\
$R^{2}$ & $>0.60$ & 0.75 & 0.69 \\
PBIAS & $\pm 15 \%$ & $+13 \%$ & $+18 \%$ \\
\hline
\end{tabular}

Note: ${ }^{a}$ Based on criteria reported in Moriasi et al. $(2015)^{[32]}$

Using the calibrated and validated SWAT model, the discharges of the 23 ungauged small rivers flowing into the lake were simulated from 2013 to 2014 . The average runoff-precipitation ratios were 0.58 on the north side, 0.68 on the west side (excluding Hii River), 0.64 on the south side, and 0.74 for the Hii River. The annual discharges fluctuated in each year. The contribution to the average annual discharge was $80.9 \%$ from the Hii River, 3.5\% from the north side, 9.8\% from the west side (excluding the Hii River), and 5.8\% from the south side. From this result, it is again evident that the Hii River is the largest contributor to water quantity in the lake and that the other (smaller) rivers contribute $19.1 \%$ of the total discharge to the lake.

\subsection{Contribution of river watersheds to water quality}

From the model results, it was seen that the Hii River contributed $80.9 \%$ of total inflow to Lake Shinji. Using this information, together with the average water quality parameters observed monthly for almost two years, the annual load discharges from the surrounding rivers were estimated (Figure 5). The SS load discharged from the Hii River contributed $82.6 \%$ of the total inflow of SS to the lake, i.e., a slightly higher contribution than the proportion of flow from the river. Contributions from the north, west, and south sides of the lake were $3.6 \%, 9.6 \%$ and $4.2 \%$, 
respectively. For the north and west sides, these percentages were also close to their relative contributions of flow, because significant differences in SS concentration were not observed among the target rivers.

The Hii River was the largest contributor of TN to the lake, at $80.0 \%$, but the influence of the rivers on the north side was $2.1 \%$ higher than their relative flow contribution. For TP, the influence of the Hii River was $71.8 \%, 9.1 \%$ lower than its relative flow contribution. However, on the north and south sides of the lake, the contributions of TP were higher than the relative flow contributions from these two areas. This indicates that although the largest catchment (in this case Hii River) made the greatest contribution to lake water quality, the total load discharges (especially TP) from small rivers may have been previously underestimated by excluding their contribution from the analysis. Therefore, along with consideration of the Hii River watershed, it is very important to evaluate the impact of small rivers on the water quality in Lake Shinji.

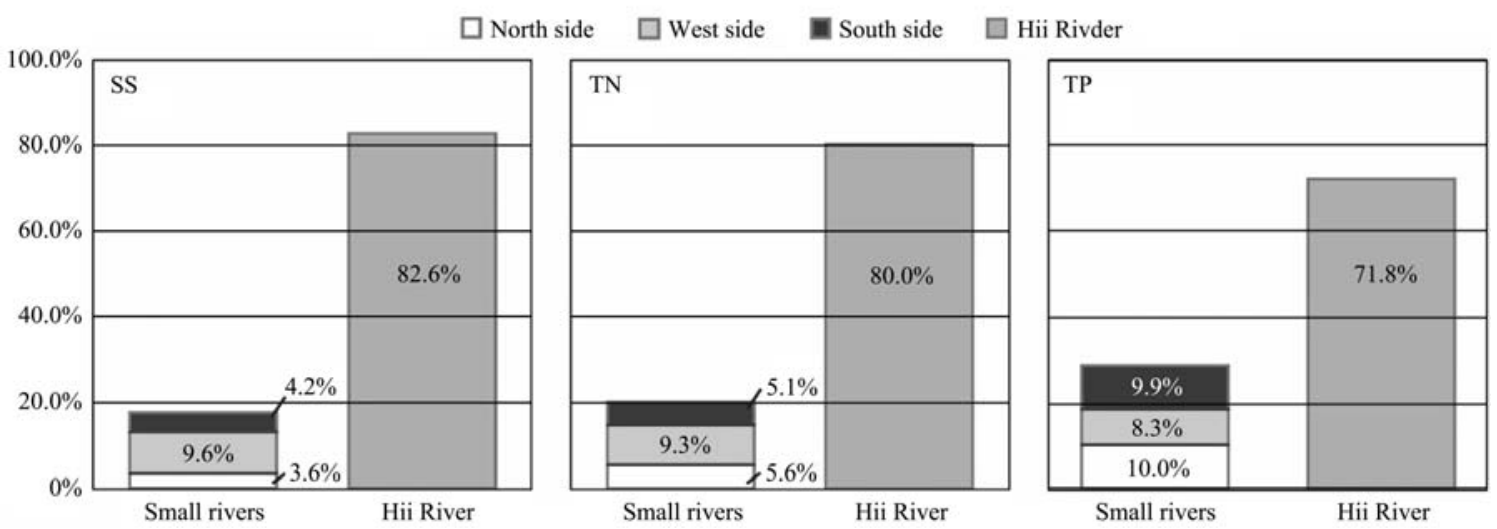

Figure 5 Contribution to nutrient and sediment loads to Lake Shinji, comparison of small rivers to Hii River

\section{Conclusions}

In this study, ungauged small rivers inflowing to Lake Shinji were analyzed, and their contributing SS, TN, and TP loads to the lake were evaluated. The results of the study can be summarized as follows.

1) The SS, TN, and TP concentrations of 10 small rivers and the Hii River inflowing to Lake Shinji were measured. It was found that the average concentrations of TN and TP exceeded the environmental water quality standards of the lake.

2) The ungauged discharges of 23 small rivers were simulated, and it was observed that the Hii River contributed $80.9 \%$ of the total inflow to the lake, with the remaining $19.1 \%$ from the surrounding small rivers.

3) The contribution of each river to the lake water quality was evaluated, and it was found that the Hii River had the largest impact on all three measures of quality in the lake. The magnitudes of these contributions were similar to the river's relative contribution of flow into the lake. However, for TP, the contribution of the surrounding small rivers was $9.1 \%$ higher than their relative flow contribution.

The impact of rivers on the lake water quality will be underestimated if only the major river is selected as a target study area. This could have important implications for the ability to manage environmental quality in the lake. To improve modeling accuracy, it is important to start gauging small rivers to calibrate the model parameters with small river discharges. This will allow for further detailed analysis of the future lake water quality, such as the responses to land use and climate change.

\section{Acknowledgements}

This study was partially supported by two grants-in-aid for scientific research: KAKENHI: 24780234 and 25281054. Hii River discharge and some precipitation data were provided by the Izumo River Office of the Ministry of Land, Infrastructure, Transport and Tourism, Japan.

\section{[References]}

[1] Akkoyunlu A, Akiner M E. Pollution evaluation in streams using water quality indices: A case study from Turkey's Sapanca Lake Basin. Ecol. Indic., 2012; 18: 501-511. doi: 10.1016/j.ecolind.2011.12.018.

[2] Scheren P A G M, Zanting H A, Lemmens A M C. Estimation of water pollution sources in Lake Victoria, East Africa: application and elaboration of the rapid assessment methodology. J. Environ. Manag., 2000; 58(4): 235-248. doi: 10.1006/jema.2000.0322.

[3] Machiwa P K. Water quality management and sustainability: the experience of Lake Victoria Environmental Management Project (LVEMP)—Tanzania. Phys. Chem. Earth, 2003; 28: 20-27. 1111-1115. doi.org/10.1016/j.pce.2003.08.032.

[4] Le C, Zha Y, Li Y, Sun D, Lu H, Yin B. Eutrophication of lake waters in China: Cost, Causes, and Control. Environ. Manag., 2010; 45(4): 662-668. doi: 10.1007/s00267-010-9440-3.

[5] Arbuckle K E, Downing J A. The influence of watershed land use on lake N: P in a predominantly agricultural landscape. Limnol. Oceanogr., 2001; 46(4): 970-975. doi: 10.4319/1o.2001.46.4.0970.

[6] Carpenter S R, Caraco N F, Correll D L, Howarth R W, Sharpley A N, Smith VH . Nonpoint pollution of surface waters with phosphorus and nitrogen. Ecol. Appl., 1998; 8(3): 559-568. doi: 10.1890/1051-0761 (1998)008[0559:NPOSWW]2.0.CO;2.

[7] Seehausen O, van Alphen J J M, Witte F. Cichlid fish diversity threatened by eutrophication that curbs sexual selection. Science, 1997; 277(5333): 1808-1811. doi: 10.1126/science.277.5333.1808.

[8] Carpenter S R, Bolgrien D, Lathrop R C, Stow C A, Reed T, Wilson M A. Ecological and economic analysis of lake eutrophication by nonpoint pollution. Aust. J. Ecol., 1998; 23(1): 68-79. doi: 10.1111/j.14429993.1998.tb00706.x.

[9] Smith V H, Tilman G D, Nekola J C. Eutrophication: impacts of excess nutrient inputs on freshwater, marine, and terrestrial ecosystems. Environ. Pollut., 1999; 100(1-3): 179-196. doi: 10.1016/S0269-7491(99) 00091-3.

[10] Kotak B G, Kenefick S L, Fritz D L, Rousseaux C G, Prepas E E, Hrudey $\mathrm{S}$ E. Occurrence and toxicological evaluation of cyanobacterial toxins in Alberta lakes and farm dugouts. Water Res., 1993; 27(3): 495-506. doi: 10.1016/0043-1354(93)90050-R.

[11] McComb A J, Davis J A. Eutrophic waters of southwestern Australia. Fertil. Res., 1993; 36(2): 105-114. doi: 10.1007/BF00747580.

[12] Arnold J G, Srinivasan R, Muttiah R S, Williams J R. Large area hydrologic modeling and assessment part I: model development. J. Am. Water Resour. Assoc., 1998; 34(1): 73-89. doi:10.1111/j.1752-1688. 1998.tb05961.x. 
[13] Arnold JG, Moriasi DN, Gassman PW, Abbaspour KC, White MJ, Srinivasan R, et al. SWAT: Model use, calibration, and validation. Trans. ASABE. 2012; 55(4): 1491-1508. doi: 10.13031/2013.42256.

[14] Williams J R, Arnold J G, Kiniry J R, Gassman P W, Green C H. History of model development at Temple, Texas. Hydrol. Sci. J., 2008; 53(5): 948-960. doi: 10.1623/hysj.53.5.948.

[15] Cibin R, Athira P, Sudheer K P, Chaubey I. Application of distributed hydrological models for predictions in ungauged basins: a method to quantify predictive uncertainty. Hydrol. Process., 2014; 28: 2033-2045. doi: 10.1002/hyp.9721.

[16] Gitau MW, Chaubey I. Regionalization of SWAT model parameters for use in ungauged watersheds. Water, 2010; 2: 849-871. doi: 10.3390/w2040849.

[17] Shimane Prefecture. The sixth lake water quality conservation plan for Lake Shinji. http://www.pref.shimane.lg.jp/shinjiko_nakaumi/ dai_6_kosyou_keikaku/index.data/6ki_shinjiko.pdf (2015.7.16). Accessed on [2006-04-24]. (in Japanese)

[18] Seto K, Nakayama D, Tanaka H, Yamaguchi K. Cyanobacterial water-bloom in Lake Shinji and its geochemical features. Laguna, 2000; 7: 61-69. (in Japanese)

[19] Abbaspour K C, Yang J, Maximov I, Siber R, Bogner K, Mieleitner J, Zobrist J, Srinivasan R. Modelling hydrology and water quality in the pre-alpine/alpine Thur watershed using SWAT. J. Hydrol.. 2007; 333:413-430. doi: 10.1016/j.jhydrol.2006.09.014.

[20] GSI: Geospatial Information Authority of Japan. Foundation map information. http://www.gsi.go.jp/kiban/index.html. Accessed on [2006-06-12].

[21] MLIT: Ministry of Land, Infrastructure, Transport and Tourism. National Land Numeral Information. http://nlftp.mlit.go.jp/ksj/ index.html. Accessed on [2006-04-24].

[22] MLIT: Ministry of Land, Infrastructure, Transport and Tourism. 1:200,000 Basic survey of land classification. http://nrb-www. mlit.go.jp/kokjo/inspect/inspect.html. Accessed on [2006-04-24].
[23] JMA: Japan Meteorological Agency. Past weather data. http://www.jma.go.jp/jma/index.html. Accessed on [2006-04-24].

[24] FAO: Food and Agriculture Organization. Crop Evapotranspiration guidelines for computing crop water requirements -. In: Irrigation and Drainage Paper No.56 (eds. Allen RG, Pereira LS, Raes D, Smith M). FAO: Rome, Italy; 1998; 290. ISBN 92-5-104219-5.

[25] ASCE: American Society of Civil Engineers. Criteria for evaluation of watershed models. J. Irrig. Drain. Eng., 1993; 119 (3): 429-442.

[26] Krause P, Boyle D P, Bäse F. Comparison of different efficiency criteria for hydrological model assessment. Adv. Geosci., 2005; 5: 89-97. doi: 10.5194/adgeo-5-89-2005.

[27] Gassman P W, Reyes M R, Green C H, Arnold J G. The soil and water assessment tool: historical development, applications, and future research directions. T ASABE, 2007; 50(4): 1211-1250. doi: 10.13031/ 2013.23637

[28] Gassman P W, Sadeghi A M, Srinivasan R. Applications of the SWAT Model Special Section: Overview and Insights. J. Environ. Qual., 2014; 43(1): 1-8. doi: 10.2134/jeq2013.11.0466.

[29] Bressiani D d A, Gassman P W, Fernandes J G, Garbossa L H P, Srinivasan R, Bonumá N B, et al. A review of Soil and Water Assessment Tool (SWAT) applications in Brazil: Challenges and prospects. Int. J. Agric. \& Biol. Eng., 2015; 8(3): 9-35. doi: 10.3965/j.ijabe. 20150803.1765 .

[30] Nash J E, Sutcliffe J V. River flow forecasting through conceptual models. Part I: A discussion of principles. J. Hydrol., 1970; 10: 282-290. doi: 10.1016/0022-1694(70)90255-6.

[31] Gupta H V, Sorooshian S, Yapo P O. Status of automatic calibration for hydrologic models: Comparison with multilevel expert calibration. J. Hydrol. Eng., 1999; 4(2): 135-143. doi: 10.1061/(ASCE)10840699(1999)4:2(135).

[32] Moriasi D N, Gitau M W, Pai N, Daggupati P. Hydrologic and water quality models: performance measures and evaluation criteria. $\mathrm{T}$. ASABE, 2015; 58(6): 1763-1785. doi: 10.13031/trans.58.10715. 